\title{
Engaging the older cancer patient; Patient Activation through Counseling, Exercise and Mobilization - Pancreatic, Biliary tract and Lung cancer (PACE-Mobil-PBL) - study protocol of a randomized controlled trial
}

Marta Kramer Mikkelsen ${ }^{1,2^{*}}$ (D), Cecilia Margareta Lund ${ }^{2,9}$, Anders Vinther ${ }^{3,4}$, Anders Tolver ${ }^{5}$, Anne-Mette Ragle ${ }^{3}$, Julia Sidenius Johansen 2,6,9, Inna Chen², Lotte Engell-Noerregaard², Finn Ole Larsen², Bo Zerahn',

Dorte Lisbet Nielsen ${ }^{2,6+}$ and Mary Jarden ${ }^{1,8+}$

\begin{abstract}
Background: Several intervention studies have demonstrated that exercise training has beneficial effects among cancer patients. However, older cancer patients are underrepresented in clinical trials, and only few exercise-based studies have focused specifically on older patients with cancer. In particular, research investigating the effects of exercise training among older patients with advanced cancer is lacking. The purpose of the current study is to investigate the effect of a 12-week multimodal and exercise-based intervention among older patients ( $\geq 65$ years) with advanced pancreatic, biliary tract or lung cancer, who are treated with first-line palliative chemotherapy, immunotherapy or targeted therapy.

Methods: PACE-Mobil-PBL is a two-armed randomized controlled trial. Participants will be randomized 1:1 to an intervention group $(N=50)$ or a control group $(N=50)$. Participants in the intervention group will receive standard oncological treatment and a 12-week multimodal intervention, comprised of: (I) supervised exercise training, twice weekly in the hospital setting, (II) home-based walking with step counts and goal-setting, (III) supportive and motivational nurse-led counseling, and (IV) protein supplement after each supervised training session. Participants in the control group will receive standard oncological treatment. The primary outcome is physical function measured by the 30-s chair stand test. Secondary outcomes include measures of feasibility, activity level, physical capacity and strength, symptom burden, quality of life, toxicity to treatment, dose reductions, inflammatory biomarkers, body weight and composition, hospitalizations and survival. Assessments will be conducted at baseline, and after 6,12 and 16 weeks.

\footnotetext{
* Correspondence: marta.kramer.mikkelsen.02@regionh.dk

†Dorte Lisbet Nielsen and Mary Jarden contributed equally to this work.

${ }^{1}$ Department of Oncology and Hematology, Rigshospitalet, Copenhagen

University Hospital, Blegdamsvej 9, 2100 Copenhagen $\varnothing$, Denmark

${ }^{2}$ Department of Oncology, Herlev and Gentofte Hospital, Copenhagen

University Hospital, Herlev Ringvej 75, 2730 Herlev, Denmark

Full list of author information is available at the end of the article
}

(c) The Author(s). 2018 Open Access This article is distributed under the terms of the Creative Commons Attribution 4.0 International License (http://creativecommons.org/licenses/by/4.0/), which permits unrestricted use, distribution, and reproduction in any medium, provided you give appropriate credit to the original author(s) and the source, provide a link to the Creative Commons license, and indicate if changes were made. The Creative Commons Public Domain Dedication waiver (http://creativecommons.org/publicdomain/zero/1.0/) applies to the data made available in this article, unless otherwise stated. 
(Continued from previous page)

Discussion: The current study is one of the first to investigate the effect of an exercise-based intervention specifically targeting older patients with advanced cancer. PACE-Mobil-PBL supports the development of health promoting guidelines for older patients with cancer, and the study results will provide new and valuable knowledge in this understudied field.

Trial registration: The study was prospectively registered at ClinicalTrials.gov on January 26, 2018 (ID: NCT03411200).

Keywords: Advanced cancer, Biliary tract cancer, Cancer, Counseling, Exercise, Lung cancer, Mobilization, Multimodal intervention, Older, Pancreatic cancer, Physical activity

\section{Background}

Advanced age is the leading risk factor for development of cancer overall, and approximately $60 \%$ of all cancers in Europe and in the USA are diagnosed among patients aged 65 years or older $[1,2]$. Although the risk of cancer increases with age, and the number of older patients with cancer is expected to rise in the coming years $[3,4]$, research on older patients with cancer is limited $[1,4]$. Aging involves a continuum of changes in function, biological, psychological, and social structures that vary depending on individual differences. In a biological view, aging causes changes in the organism that lead to a decline in organ functions and in physiological reserves [5-8]. Comorbidity, defined as the occurrence of two or more medically diagnosed diseases, increases with age and heightens the risk of disability and mortality $[9,10]$. In addition, use of multiple drugs for multiple diseases, also known as polypharmacy, leads to an increased risk of drug interactions, adverse reactions and poor adherence [11].

\section{Cancer and aging}

Aging itself is associated with limitations in physical function and reduced reserve capacity. A diagnosis of cancer and its accompanying treatments can lead to numerous symptoms and side effects, physical disability, psychological distress and increased health care needs [12]. The interplay between age-related and cancer-related declines in health increases vulnerability and risk of development of short- and long-term disabilities [13, 14]. Older patients with cancer have a higher incidence of limitations in activities of daily living (ADL), reduced quality of life (QoL), and a higher prevalence of geriatric syndromes such as depression, falls and osteoporosis compared to older adults without a history of cancer $[15,16]$. Research suggests that older patients with cancer benefit from chemotherapy similar to younger patients $[17,18]$. However, older patients with cancer are at increased risk of toxicity due to age-related physiological changes [19].

\section{Sarcopenia and cachexia}

Loss of muscle mass and strength is a part of the normal aging process and is referred to as primary sarcopenia [20]. Sarcopenia has multiple contributing factors including aging itself, insufficient nutrition, sedentary lifestyle or bedrest. The term secondary sarcopenia is often used to describe sarcopenia that is caused by other factors such as cancer or other chronic diseases [20]. Cachexia is another depleting syndrome that causes weight loss and muscle wasting due to an underlying disease [21]. The pathophysiology of cancer cachexia includes a complex combination of reduced energy intake and uptake, hormonal alterations, abnormal metabolism and inflammation [21]. Previous studies have identified cachexia and sarcopenia as contributors to impaired physical functioning [22], reduced tolerance to anti-cancer treatment $[23,24]$, higher symptom burden [25], reduced QoL $[25,26]$ and increased mortality $[24,27,28]$ among patients with cancer.

\section{Exercise training}

Research has shown that exercise training (e.g. aerobic training, resistance training, and balance and flexibility exercises) is safe and beneficial for older people [29-31]. Documented effects include increased muscle mass and strength, functional mobility and ADL function, improved QoL, and reduction of falls and depressive symptoms [29-32]. The effect of exercise training has also been widely investigated in cancer patients [33-35]. A myriad of beneficial effects of exercise training have been documented, including reduced severity of cancer and treatment-related symptoms and side effects, as well as improved aerobic capacity, muscle strength, physical functioning and QoL [33-36]. However, older patients are underrepresented in clinical trials, and only few exercise-based intervention studies have focused specifically on older patients with cancer [37]. Among the few studies that have investigated the effect of exercise training in older patients with cancer, most have focused on older patients with early-stage breast, prostate and colorectal cancer. Especially, research investigating the effect of exercise training in older patients with advanced cancer is lacking [37].

\section{Pancreatic, biliary tract and lung cancer}

With median ages around 65 to 70 years at diagnosis, pancreatic cancer (PC), biliary tract cancer (BTC) and 
lung cancer (LC) are malignancies highly associated with aging. These cancers are most often diagnosed at an advanced stage, and therefore the majority of patients are treated with palliative therapies. Focusing on LC, several previous studies have provided evidence that exercise training is feasible, safe and beneficial for patients with LC before, during and after anti-cancer treatment [38-41]. Demonstrated effects include reduced surgical complications, reduced levels of symptoms and side effects, and improvements in physical function and capacity [38-41]. Only one prior exercise-based study has focused specifically on older patients with LC. In this study, Lai et al. [42] investigated the effect of a short-term preoperative pulmonary rehabilitation program in 60 older patients ( $\geq 70$ years) with non-small cell LC (NSCLC) scheduled to lobectomy, and demonstrated significant improvements in functional capacity and peak expiratory flow, as well as reductions in length of hospital stay and post-operative complications. Exercise training for patients with PC and BTC is a relatively unexplored research field. In a randomized controlled trial, Yeo et al. [43] investigated the effect of a 12-week home-based walking program in 102 patients with resected PC or periampullary cancer. After study completion, patients in the intervention group were walking twice as far as patients in the control group, and had significant reductions in pain and fatigue, as well as improved self-reported physical functioning [43]. In a pilot study from 2014, Jensen et al. [44] investigated the feasibility of exercise training in 26 patients with advanced gastrointestinal cancers undergoing palliative chemotherapy. Patients were randomized to one of two groups; resistance training or aerobic exercise on a bicycle ergometer for 12 weeks. In both groups, a significantly decreased level of fatigue was demonstrated from pre to post-assessment, and sleep quality was also significantly improved. However, only minor improvements were seen in a few domains of QoL measures, and no improvements were demonstrated in nausea/vomiting, constipation, dyspnea or appetite/anorexia [44]. No prior studies have investigated the effect of an exercise program specifically for older patients with PC or BTC.

\section{Aim}

The aim of the current study is to investigate the effect of a 12-week multimodal and exercise-based intervention in older patients newly diagnosed with advanced PC, BTC or $\mathrm{LC}$ who are undergoing first-line palliative chemotherapy, immunotherapy or targeted therapy.

\section{Hypothesis}

We hypothesize that with a multimodal and exercise-based intervention, participants will maintain physical function. In addition, we believe that participants in the intervention group will have reductions in symptoms and side effects, improved QoL and psychological wellbeing, limited weight loss and muscle wasting, and increased treatment tolerance, compared to participants in the control group.

\section{Methods \\ Design}

PACE-Mobil-PBL is a prospective two-armed randomized controlled trial. The study is planned to include 100 patients with advanced PC, BTC or LC, who are treated with first-line palliative chemotherapy, immunotherapy or targeted therapy at the Department of Oncology at Copenhagen University Hospital, Herlev and Gentofte, Denmark. The overall study design is illustrated in Fig. 1. This article describes the design of the study and complies with the SPIRIT guidelines for randomized controlled trial protocols, and with the Consensus on Exercise Reporting Template (CERT) recommendations for reporting exercise programs in clinical trials [45].

\section{Participants}

Patients are eligible for inclusion if the following criteria are fulfilled: 1) diagnosis with locally advanced or metastatic PC, BTC or NSCLC within 12 weeks; 2) unresectable cancer; 3) treatment with first-line palliative chemotherapy, immunotherapy or targeted therapy; 4) age $\geq 65$ years; 5) Eastern Cooperative Oncology Group (ECOG) performance status score $\leq 2 ; 6$ ) ability to speak and read Danish, and to provide a signed informed consent form (ICF).

Exclusion criteria are: 1) any physical condition that hinders the execution of physical exercise training; 2) small-cell LC; 3) documented and uncontrolled brain metastases that hinder study participation based on the referring oncologist's assessment; 4) dementia, psychotic disorders or cognitive diseases or conditions that hinder participation in an exercise-based clinical trial; 5) unstable medical disease or a history of serious or concurrent illness (any medical condition that might be aggravated by exercise training or that cannot be controlled). Patients with documented bone metastases will be excluded from participation if they have a bone metastatic burden or location that poses a risk of pathologic fractures in the performance of exercise training, as assessed by the referring oncologist.

After the initial screening procedure, the research team will obtain ICF and collect all relevant baseline data before randomization.

\section{Patient involvement}

With the aim of involving patients in the research process, individual semi-structured interviews were conducted in older patients with advanced PC, BTC and LC, before the final intervention program was developed. The aim of these pre-interviews was to gain insight into how patients experience and manage symptoms and side effects, to 


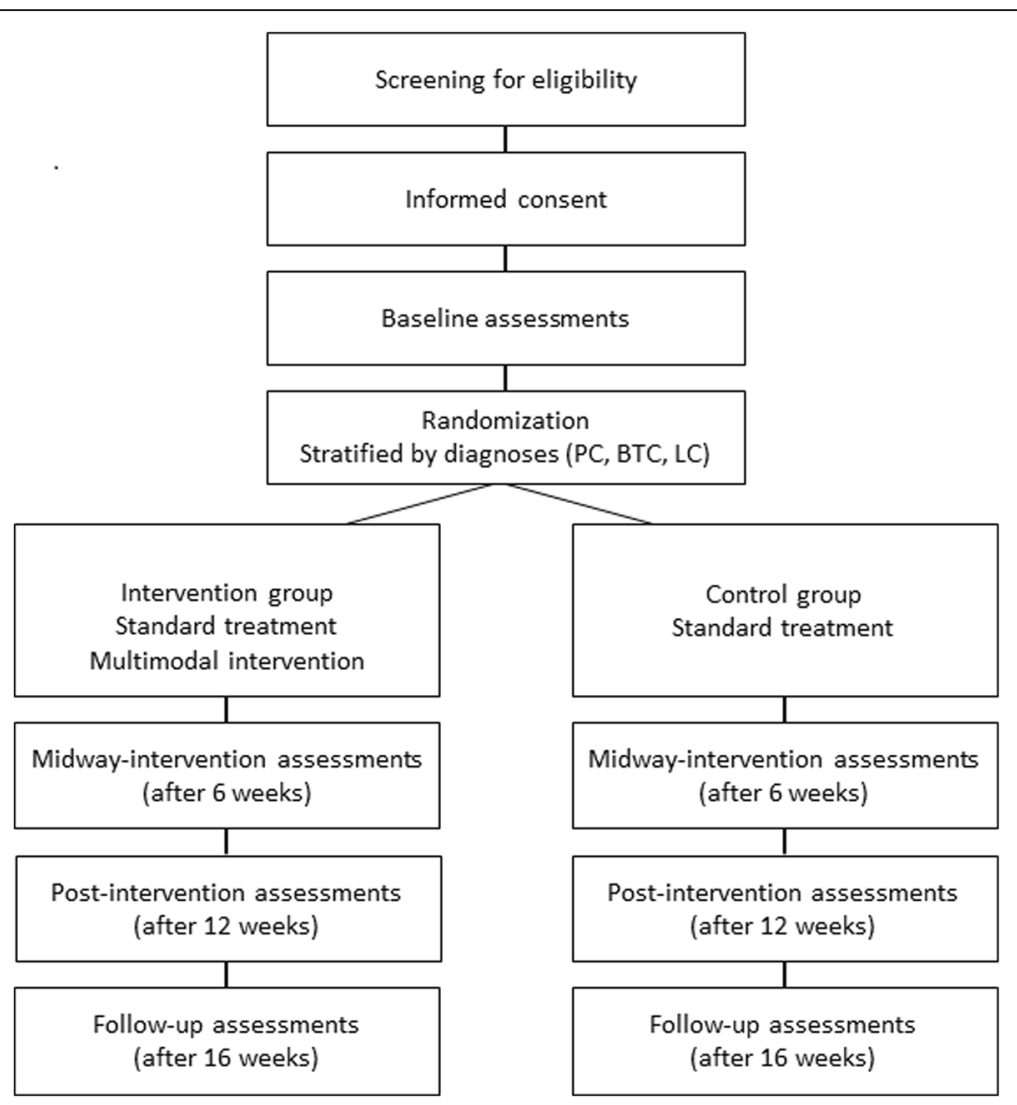

Fig. 1 PACE-Mobil-PBL study design. Abbreviations: BTC (biliary tract cancer), LC (lung cancer), PC (pancreatic cancer)

explore their views on exercise training during oncological treatment, and to get their expert advice on the optimal recruitment procedure, intervention composition, and on relevant outcome measures (unpublished results).

\section{Randomization}

After inclusion and baseline assessments, participants are randomly allocated to the intervention group or the control group using a 1:1 block randomization. The block size will only be known by the statistician carrying out the randomization procedure. Randomization will be stratified on diagnosis by using separate randomization lists for each diagnosis group (PC, BTC and LC). The 'blockrand' package of the statistical software $\mathrm{R}$ was used to generate all randomization lists. Randomization will be administered via the web-based research platform REDCap (Research Electronic Data Capture). Source codes to generate all randomization lists are stored to ensure full reproducibility.

\section{Intervention}

Participants in the intervention group will receive standard oncological treatment and a 12-week multimodal exercise-based intervention comprised of the four following components:
\#1: Supervised and group-based exercise training at the hospital setting; two times a week for sessions of approximately $60 \mathrm{~min}$. The program consists of warm-up exercises of light to moderate intensity, including exercises for balance and flexibility, and a program of progressive resistance training (PRT) that comprises seven resistance training exercises targeting the large muscle groups. In the first two weeks, participants will be introduced to the PRT program, starting with high repetition numbers and low loads. During the intervention period, the volume of the PRT will progress from two to three sets, and the load will increase from 15 to 10 repetitions maximum (yielding a heavier load relative to each participant's maximum). The progression will be tailored to each individual participant. Three experienced physiotherapists (range 6-17 years) will supervise all training sessions. Training sessions will be performed in groups of up to 12 participants at the rehabilitation facilities at Herlev and Gentofte Hospital, where appropriate strength training equipment is available (Technogym Element series, Gambettola, Italy). For detailed description of the supervised exercise program see Table 1. 
Table 1 Description of the supervised exercise program

\begin{tabular}{|c|c|}
\hline $\begin{array}{l}\text { Duration of exercise } \\
\text { program }\end{array}$ & 12 weeks (24 sessions) \\
\hline $\begin{array}{l}\text { Duration of exercise } \\
\text { sessions }\end{array}$ & $\begin{array}{l}60 \text { min ( } 10 \text { min of warm-up, } 45 \text { min of PRT } \\
\text { and } 5 \text { min of stretching) }\end{array}$ \\
\hline Exercise frequency & 2 times a week \\
\hline $\begin{array}{l}\text { Rest period between } \\
\text { exercise sessions }\end{array}$ & $2-5$ days \\
\hline Warm-up & $\begin{array}{l}\text { Exercises of light to moderate intensity with } \\
\text { elements of balance and flexibility training } \\
\text { (e.g. walking around in circles with changing } \\
\text { directions, walking on toes and heels, floor } \\
\text { touch, walking lunges, exercises on balance } \\
\text { board) }\end{array}$ \\
\hline $\begin{array}{l}\text { Description of PRT } \\
\text { exercises }\end{array}$ & $\begin{array}{l}\text { Chest press, abdominal crunch, leg press, leg } \\
\text { curl (hamstrings), leg extension (quadriceps), } \\
\text { lower back and low row }\end{array}$ \\
\hline $\begin{array}{l}\text { No. of repetitions } \\
\text { (PRT) }\end{array}$ & $\begin{array}{l}15 \text { RM (session 1-2), } 12 \text { RM (session 3-13), } \\
10 \text { RM (session 14-24) }\end{array}$ \\
\hline $\begin{array}{l}\text { No. of sets per session } \\
\text { (PRT) }\end{array}$ & 2 (session 1-6), 3 (session 7-24) \\
\hline $\begin{array}{l}\text { Rest period between } \\
\text { sets (PRT) }\end{array}$ & $60 \mathrm{~s}$ \\
\hline
\end{tabular}

Abbreviations: No. (number), $P R T$ progressive resistance training, $R M$ repetition maximum

\section{\#2: Nutritional supplement after supervised exercise} training; to prevent a negative energy balance on training days, a protein supplement (e.g. protein drink or bar, 227-300 cal and 12-20 g protein) will be served for participants after each training session.

\#3: An individualized activity program with steps counts, goal-setting and evaluation; based on each participant's starting point, preferences and motivation, an individualized activity program will be conducted with the overall aim of maintaining or increasing the level of daily activity. The level of activity will be measured as steps counts with a Garmin Vivofit 3 activity tracker (Garmin, Olathe, Kansas, U.S.). Goal-setting and evaluation in relation to walked steps will be conducted once weekly, face-to-face or by telephone, in collaboration between each participant and a member of the research team.

\#4: Motivational and supportive counseling; participants in the intervention group will participate in two sessions of individualized nurse-led counseling. The first session will be held immediately after study entry, and the second will be conducted after 6 weeks. Counseling will be based on a holistic assessment of each participant's life situation and potential challenges. Each participant will be asked about potential problems in different life domains (physical, functional, psychological/emotional, social, and existential/spiritual). Based on identified needs, participants will be challenged with questions about the characteristics of the problem(s), factors that may influence the problem(s), and their problem management strategy. The purpose of this process is to activate the participants and to promote self-management. Also, advice and counseling on identified problems will be provided, and followed up if needed. If participants present any complex medical problems, they will be encouraged to contact their oncologist or general practitioner, as appropriate. As mandatory components, all participants will be informed about expected bodily reactions to exercise training, and advised about sufficient nutrition during the intervention. If participants need specialized nutritional counseling, they will be referred to a dietician.

\section{Controls}

Participants in the control group will receive standard oncological treatment. No restrictions on physical activity are made for control participants.

\section{Study outcome measures}

The primary endpoint is the between-group difference in within-group changes in physical capacity and lower extremity strength measured with the 30-s chair stand test (30s-CST) at the post-intervention assessment. Secondary endpoints include feasibility measures, adverse events, and changes in functional performance, muscle strength, body composition, body weight, patient-reported performance status, symptom burden, symptoms of depression and anxiety, QoL, physical activity, treatment tolerance and toxicity, inflammatory biomarkers, hospital admissions and mortality. The outcome measures for both groups are described in the following section.

\section{Physical tests}

To measure physical function and lower extremity strength, the 30s-CST will be used (primary outcome) [46]. The 30 s-CST is considered as highly relevant for older patients with cancer, as the ability to rise from a chair is regarded a prerequisite for functional independence. The 30s-CST is a widely used and validated physical measure, especially among older people, and it has also been used and tested among patients with cancer [47-49]. Physical performance will also be assessed with a 6 and 10-m gait speed test. Gait speed is a suitable measure to use in a clinical rehabilitation setting, and has a documented predictive value for functional and cognitive decline, falls, independence, and mortality $[50,51]$. To measure physical capacity and endurance, the six-minute-walk test (6MWT) will be used [46]. The $6 \mathrm{MWT}$ measures the distance an individual is able to walk over a total of six minutes on a hard and flat surface. The 
test was originally developed for use in frail older patients, but has been used and validated in a variety of different populations [52, 53]. To measure physical function and strength of the upper body, the handgrip strength test will be used [54]. Research has shown that handgrip strength may be independently associated with functional capacity, QoL and survival in patients with advanced cancer [55]. Detailed descriptions of the performance of physical tests can be found in an additional file (see Additional file 1).

\section{Feasibility measures}

Feasibility of the intervention will be evaluated as acceptability, attrition and adherence. Acceptability will be measured as the number of eligible patients who agree to participate in the study. Reasons for declining study participation will be listed and evaluated. Attrition will be registered as the number and percentage of participants who do not complete the study requirements. For each component of the intervention adherence will be assessed as the percentage of study parts completed. Data on adverse events related to the intervention will be monitored according to the National Cancer Institute Common Terminology Criteria for Adverse Events, version 4.0 (NCI CTCAE v4.0).

\section{Patient-Reported Outcome Measures (PROM)}

Patient-reported performance status (PRPS) will be assessed using the ECOG performance status [56]. To measure symptom burden, the M.D. Anderson Symptom Inventory (MDASI) version 1 will be used [57]. MDASI is a multi-symptom PROM assessing the severity of symptoms and their interference with daily living [57]. To assess QoL, the European Organisation for Research and Treatment of Cancer Quality of Life Questionnaire C30 (EORTC QLQ-C30) version 3.0 will be applied [58]. The EORTC-QLQ-C30 is designed to be cancer specific, and consists of 30 items distributed throughout different functional and symptom scales [58]. To assess symptoms of depression and anxiety, the Hospital Anxiety and Depression Scale (HADS) version 3.0 will be used [59]. HADS comprises 14 items and is designed to measure general depression and anxiety by self-administration [59].

\section{Physical activity}

Level of physical activity will be measured by step counts using a Garmin Vivofit 3 activity tracker (Garmin, Olathe, Kansas, U.S.). The average number of steps walked measured over three consecutive days will be used as an estimate of physical activity.

\section{Qualitative assessment of participants' experiences}

Qualitative semi-structured interviews will be conducted with a sample of participants from the intervention group post intervention to explore participants' experiences and satisfaction with the intervention.

\section{Treatment tolerance and toxicity}

Data on dose-reductions and treatment discontinuations will be registered prospectively throughout the intervention period. Toxicity will be registered according to the NCI CTCAE v4.0.

\section{Body measures}

Weight, height and body mass index (BMI) will be assessed using standard procedures (no shoes, light clothing). Body composition will be assessed by whole-body dual-energy x-ray absorptiometry (DXA) scan (GE lunar iDXA, GE Healthcare Technologies, Madison, Wisconsin, U.S.), and by bioelectrical impedance (BI) assessment (Body Composition Monitor, Fresenius Medical Care, Bad Homburg v.d.H., Germany).

\section{Inflammatory biomarkers}

To explore the influence of exercise training on inflammation, data on inflammatory biomarkers C-reactive protein (CRP), interleukin 6 (IL-6), and Chitinase-3-like protein 1 (CHI3L1), also known as YKL-40, will be collected from medical records or through cooperative research projects.

\section{Hospital admissions}

Data on number, causes, and length of hospitalization during the study period will be collected from medical records.

\section{Mortality/survival}

Incidences of deaths and causes of deaths will be registered throughout the study period by review of medical records.

Frequency and timing of study assessments are shown in Table 2. REDCap will continuously be used for data entry during the study period, and subsequently for data storage.

\section{Blinding procedures}

Assessments of the primary outcome 30s-CST and all other physical tests will be performed by blinded physiotherapists. Due to the nature of the study, study participants are not blinded.

\section{Statistics}

\section{Sample size}

No prior studies have investigated the clinically important difference in the 30s-CST in patients with cancer. According to a previous study focusing on patients with osteoarthritis, the clinically important change in the 
Table 2 Schedule of study assessments

\begin{tabular}{|c|c|c|c|c|c|c|c|c|c|c|c|c|c|c|c|c|}
\hline Time (week no.) & -2 to 0 & 0 & 1 & 2 & 3 & 4 & 5 & 6 & 7 & 8 & 9 & 10 & 11 & 12 & 13 & 17 \\
\hline \multicolumn{17}{|l|}{ Enrollment } \\
\hline Eligibility screen & $x$ & & & & & & & & & & & & & & & \\
\hline Informed consent & $x$ & & & & & & & & & & & & & & & \\
\hline Randomization & & $x$ & & & & & & & & & & & & & & \\
\hline Intervention & & & $x-$ & - & - & 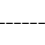 & 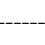 & 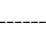 & - & & & & & $--X$ & & \\
\hline \multicolumn{17}{|l|}{ Physical tests and examinations } \\
\hline 30s-CST (primary outcome) & $x$ & & & & & & & & $x$ & & & & & & $x$ & $x$ \\
\hline $6 \mathrm{MWT}$ & $x$ & & & & & & & & $x$ & & & & & & $x$ & $x$ \\
\hline Handgrip strength & $x$ & & & & & & & & $x$ & & & & & & $x$ & $x$ \\
\hline Gait speed test & $x$ & & & & & & & & $x$ & & & & & & $x$ & $x$ \\
\hline Physical activity ${ }^{a}$ & $x$ & & & & & & & & & & & & & & $x$ & \\
\hline DXA & $x$ & & & & & & & & & & & & & & $x$ & \\
\hline $\mathrm{Bl}$ & $x$ & & & & & & & & & & & & & & $x$ & \\
\hline Body weight $^{a}$ & $x$ & & & & & & & & $x$ & & & & & & $x$ & $x$ \\
\hline Inflammatory biomarkers & $x$ & & & & & & & & $x$ & & & & & & $x$ & $x$ \\
\hline \multicolumn{17}{|l|}{ PROMs } \\
\hline PRPS & $x$ & & & & & & & & $x$ & & & & & & $x$ & $x$ \\
\hline $\mathrm{MDASI}^{\mathrm{a}}$ & $x$ & & & & & & & & $x$ & & & & & & $x$ & $x$ \\
\hline EORTC-QLQ-C30 & $x$ & & & & & & & & $x$ & & & & & & $x$ & $x$ \\
\hline HADS & $x$ & & & & & & & & $x$ & & & & & & $x$ & $x$ \\
\hline \multicolumn{17}{|l|}{ Qualitative exploration } \\
\hline Individual Interviews & & & & & & & & & & & & & & & $x$ & \\
\hline \multicolumn{17}{|l|}{ Feasibility } \\
\hline Adherence & $x$ & $x$ & $x$ & $x$ & $x$ & $x$ & $x$ & $x$ & $x$ & $x$ & $x$ & $x$ & $x$ & $x$ & & \\
\hline Attrition & $x$ & $x$ & $x$ & $x$ & $x$ & $x$ & $x$ & $x$ & $x$ & $x$ & $x$ & $x$ & $x$ & $x$ & $x$ & $x$ \\
\hline Adverse events & $x$ & $x$ & $x$ & $x$ & $x$ & $x$ & $x$ & $x$ & $x$ & $x$ & $x$ & $x$ & $x$ & $x$ & & \\
\hline \multicolumn{17}{|l|}{ Oncological treatment } \\
\hline Treatment related toxicity $^{b}$ & $x$ & $x$ & $x$ & $x$ & $x$ & $x$ & $x$ & $x$ & $x$ & $x$ & $x$ & $x$ & $x$ & $x$ & $x$ & $x$ \\
\hline Dose-reductions ${ }^{\mathrm{b}}$ & $x$ & $x$ & $x$ & $x$ & $x$ & $x$ & $x$ & $x$ & $x$ & $x$ & $x$ & $x$ & $x$ & $x$ & $x$ & $x$ \\
\hline Hospitalizations & $x$ & $x$ & $x$ & $x$ & $x$ & $x$ & $x$ & $x$ & $x$ & $x$ & $x$ & $x$ & $x$ & $x$ & $x$ & $x$ \\
\hline Survival & $x$ & $x$ & $x$ & $x$ & $x$ & $x$ & $x$ & $x$ & $x$ & $x$ & $x$ & $x$ & $x$ & $x$ & $x$ & $x$ \\
\hline
\end{tabular}

${ }^{\mathrm{a}}$ Once weekly for participants in the intervention group ${ }^{\mathrm{b}}$ Registered for every treatment course

Abbreviations: 30s-CST 30-s chair stand test, 6MWT six-minute-walk-test, Bl bioelectrical impedance, DXA whole-body dual-energy x-ray absorptiometry, EORTC-

QLQ-C30 European Organisation for Research and Treatment of Cancer Quality of Life Questionnaire C30, HADS Hospital Anxiety and Depression Scale, MDASI M.D. Anderson Symptom Inventory, PRPS patient-reported performance status

30s-CST was set at 2.6 repetitions [60]. Based on results from prior studies in patients with advanced cancer, a standard deviation (SD) of approximately 3 has been reported $[61,62]$. To be able to detect a between-group difference in the within-group changes of 2.6 repetitions in the 30s-CST, and to obtain a type I error rate of $5 \%$ and a power of $90 \%$, a sample size of 29 participants per study arm will be needed. To account for a dropout rate of approximately $40 \%$, it has been decided to increase the group size to 50 . Thus, a total of 100 participants will be included in the trial.

\section{Analyses}

Feasibility measures will be reported as numbers and percentages. Baseline characteristics will be calculated for all participants (total), and separately for the intervention and control group. For all quantitative variables the median number and interquartile range (IQR) will be calculated, and for nominal variables the number and percentage distribution will be calculated. Results from physical tests, blood test, body measures, questionnaires, hospitalizations and toxicity-measures will be reported as means and SDs or as median and IQR, as appropriate. 
Change over time in ordinal categorical values will be evaluated by a trend test using logistic regression. Within-group and between-group differences in continuous-level data will be performed using independent T-tests. Overall and cancer specific survival will be analyzed with the Kaplan-Meier method, competing risk and Cox regression analyses. The significance level of all tests is set at $p<0.05$ and analyses will be carried out in R by the program's statistician (AT).

\section{Discussion}

We have designed a randomized controlled trial to investigate the effect of a multimodal exercise-based intervention for older patients with advanced PC, BTC and LC undergoing first-line palliative treatment. The elements of exercise in the PACE-Mobil-PBL intervention are designed in accordance with Danish and international recommendations for exercise training in healthy individuals and in patients with cancer [63-65]. Focusing on older patients with advanced PC, BTC and LC, several factors have been considered in targeting the intervention, including age-related limitations and comorbidities. Due to the high incidence of cancer cachexia and sarcopenia among these patient groups, the main priority of the exercise program lies on resistance training, whereas high intensity cardiovascular training that requires high energy consumption is avoided. With the aim of avoiding inactivity, an individualized light to moderate intensity home-based activity program based on step counts will be developed for each participant. The multimodal intervention also includes two individualized counseling sessions. The aim of the counseling is to help participants to cope with their current situation in different life domains. The content related to selected domains and questions in the counseling is inspired by the comprehensive geriatric assessment, and by Danish recommendations for the basic palliative assessment [66, 67]. As patients with advanced PC, BTC and $\mathrm{LC}$ are at high risk of multiple debilitating symptoms and side effects during oncological treatment, such as fatigue, anorexia, pain, respiratory problems and psychological distress [68-70], counseling sessions will specifically focus on optimizing participants' symptom management. The approach in guiding participants to manage their symptoms and side effects is inspired by the Integrated Approach to Symptom Management developed by Larson et al. [71]. Information on sufficient nutrition during the course of cancer treatment will be incorporated as a mandatory element in the first counseling session, and a protein supplement will be served to all participants after all training sessions. Focus on nutrition is incorporated as nutritional status is recognized as an independent predictor of cancer-related outcomes such as treatment tolerance and mortality [72, 73]. Furthermore, evidence suggests that malnutrition is highly prevalent in patients with cancer, particularly among older patients with cancer [74].

In the PACE-Mobil-PBL intervention, motivation is considered a key factor in engaging participants in exercise training and symptom management, both short and long term. The approach to participants in the nurse-led counseling is inspired by the concept and techniques from Motivational Interviewing [75]. Motivational Interviewing is a collaborative and person-centered method that helps people to resolve ambivalence, and to strengthen their internal motivation needed for a behavior change. Motivational Interviewing has been applied in various settings, and has proven to be an effective counseling strategy in life style changes among patients with cancer [76]. Goal-setting is incorporated as an element in the home-based activity program, as it is recognized as an effective method to achieve behavioral changes, and to enhance motivation and self-efficacy [77].

With the aging population and expected increase in cancer incidence, especially among older people, new approaches of early rehabilitation are needed in order to maintain physical function, independence and QoL in older patients with advanced cancer. PACE-Mobil-PBL has the potential to become a new model of early rehabilitation for older patients with advanced PC, BTC and LC. In the long term, it is our goal to investigate the multimodal program's effect among older patients with various malignancies in order to map out the effects, common features and differences across cancers, with an overall focus on older patients with cancer.

\section{Additional file}

Additional file 1: Detailed description of physical tests. A detailed description of the performance of physical tests in the study, including practical conditions, tools and instructions. (DOCX $14 \mathrm{~kb}$ )

\section{Abbreviations}

30s-CST: 30-second Chair Stand Test; 6MWT: Six-Minute-Walk-Test; ADL: Activities of Daily Living; BI: Bioelectrical Impedance; BMI: Body Mass Index; BTC: Biliary Tract Cancer; CHI3L1 (YKL-40): Chitinase-3-like protein 1; CRP: C-Reactive Protein; DXA: Dual-energy X-ray Absorptiometry; ECOG: Eastern Cooperative Oncology Group; EORTC-QLQ-C30: European Organisation for Research and Treatment of Cancer Quality of Life Questionnaire C30; HADS: Hospital Anxiety and Depression Scale ICF: Informed Consent Form; IL-6: Interleukin 6; IQR: Interquartile Range; LC: Lung Cancer; MDASI: M.D. Anderson Symptom Inventory; NCI CTCAE v4.0: National Cancer Institute Common Terminology Criteria for Adverse Events, version 4.0; NSCLC: Non-Small Cell Lung Cancer; PC: Pancreatic Cancer; PROM: Patient-Reported Outcome Measure; PRPS: Patient Reported Performance Status; PRT: Progressive Resistance Training; PS: Performance Status; QoL: Quality of Life; REDCap: Research Electronic Data Capture; SD: Standard Deviation

\section{Funding}

The PACE-Mobil-PBL study is supported by grants from the Novo Nordisk Foundation (NNF16OC0022338, NNF17OC0029756). The Novo Nordisk Foundation did not have any role in the conduction of the study protocol, and 
will not have any role in data collection, interpretation of data, or in the drafting or approval of any coming publications.

\section{Availability of data and materials}

Plans for data entry, security and storage have been approved by the Danish Data Protection Agency (j.nr. VD - 2018-51). Study material and data will be available from the corresponding author Marta Kramer Mikkelsen on request.

\section{Authors' contributions}

Authorships follows the Vancouver guidelines. MKM, CML, AV, JSJ, IC, AMR, DLN and MJ designed the study. AT provided statistical assistance on the power analysis, and planned and prepared the randomization procedure. MKM wrote the protocol and the initial manuscript draft, and CML, AV, AMR, AT, JSJ, IC, LEN, FOL, BZ, DLN and MJ reviewed it critically. All authors have read and approved the final version of the manuscript.

\section{Authors' information}

MKM is a PhD student from the University of Copenhagen, with an educational background as a RN and MHSc. JSJ, IC, LEN, FOL and DLN are oncologists, CML is a geriatrician, $A V$ is a research physiotherapist, AMR is a physiotherapist, AT is a statistician, BZ is a medical physiologist, and MJ is a senior nursing researcher.

\section{Ethics approval and consent to participate}

The study protocol, version 2.0 from February 1st 2018, is approved by the Regional Ethics Committee for the Capital Region of Denmark (j.nr: $\mathrm{H}-18001096)$. Any changes in the protocol will be reported to the Regional Ethics Committee. Informed verbal and written content will be obtained for all participants before inclusion in the study.

\section{Consent for publication}

Not applicable.

\section{Competing interests}

The authors declare that they have no competing interests.

\section{Publisher's Note}

Springer Nature remains neutral with regard to jurisdictional claims in published maps and institutional affiliations.

\section{Author details}

'Department of Oncology and Hematology, Rigshospitalet, Copenhagen University Hospital, Blegdamsvej 9, 2100 Copenhagen $\varnothing$, Denmark. ${ }^{2}$ Department of Oncology, Herlev and Gentofte Hospital, Copenhagen University Hospital, Herlev Ringvej 75, 2730 Herlev, Denmark. ${ }^{3}$ Department of Rehabilitation, Herlev and Gentofte Hospital, Copenhagen University Hospital, Herlev Ringvej 75, 2730 Herlev, Denmark. ${ }^{4}$ QD-Research Unit, Herlev and Gentofte Hospital, Copenhagen University Hospital, Herlev Ringvej 75, 2730 Herlev, Denmark. ${ }^{5}$ Data Science Laboratory, Department of Mathematical Sciences, University of Copenhagen, 2100 Copenhagen $\varnothing$, Denmark. ${ }^{6}$ Department of Clinical Medicine, Faculty of Health and Medical Sciences, University of Copenhagen, 2200 Copenhagen N, Denmark. ${ }^{7}$ Department of Clinical Physiology and Nuclear Medicine, Herlev and Gentofte Hospital, Copenhagen University Hospital, Herlev Ringvej 75, 2730 Herlev, Denmark. ${ }^{8}$ Department of Public Health, Faculty of Health and Medical Sciences, University of Copenhagen, 1014 Copenhagen K, Denmark. ${ }^{9}$ Department of Medicine, Herlev and Gentofte Hospital, Copenhagen University Hospital, Herlev Ringvej 75, Herlev 2730, Denmark

Received: 7 June 2018 Accepted: 18 September 2018 Published online: 27 September 2018

\section{References}

1. Scher KS, Hurria A. Under-representation of older adults in cancer registration trials: known problem, little progress. J Clin Oncol. 2012; 30(17):2036-8

2. International Agency for Cancer Research. GLOBOCAN 2012: estimated cancer incidence, Mortality and incidence in 2012. 2012. http://globocan. iarc.fr/Pages/age-specific_table_sel.aspx. Accessed 19 Dec 2017.

3. Siegel RL, Miller KD, Jemal A. Cancer statistics, 2018. CA Cancer J Clin. 2018; 68(1):7-30.
4. Bellizzi KM, Mustian KM, Palesh OG, Diefenbach M. Cancer survivorship and aging: moving the science forward. Cancer. 2008;113(12 Suppl):3530-9.

5. Strait JB, Lakatta EG. Aging-associated cardiovascular changes and their relationship to heart failure. Heart Fail Clin. 2012;8(1):143-64.

6. Sharma G, Goodwin J. Effect of aging on respiratory system physiology and immunology. Clin Interv Aging. 2006;1(3):253-60.

7. Weinstein JR, Anderson S. The aging kidney: physiological changes. Adv Chronic Kidney Dis. 2010;17(4):302-7.

8. Bhutto A, Morley JE. The clinical significance of gastrointestinal changes with aging. Curr Opin Clin Nutr Metab Care. 2008;11(5):651-60.

9. Fried LP, Ferrucci L, Darer J, Williamson JD, Anderson G. Untangling the concepts of disability, frailty, and comorbidity: implications for improved targeting and care. J Gerontol A Biol Sci Med Sci. 2004;59(3):255-63.

10. Fried LP, Kronmal RA, Newman AB, Bild DE, Mittelmark MB, Polak JF, et al. Risk factors for 5-year mortality in older adults: the Cardiovascular Health Study. Jama. 1998;279(8):585-92.

11. Hilmer SN, Gnjidic D. The effects of polypharmacy in older adults. Clin Pharmacol Ther. 2009;85(1):86-8.

12. Cheville AL, Mustian K, Winters-Stone K, Zucker DS, Gamble GL, Alfano CM. Cancer rehabilitation: An Overview of Current Need, Delivery Models, and Levels of Care. Phys Med Rehabil Clin N Am. 2017;28(1):1-17.

13. Kenzik KM, Kent EE, Martin MY, Bhatia S, Pisu M. Chronic condition clusters and functional impairment in older cancer survivors: a population-based study. J Cancer Surviv. 2016;10(6):1096-103.

14. Grov EK, Fossa SD, Dahl AA. Short-term and long-term elderly cancer survivors: a population-based comparative and controlled study of morbidity, psychosocial situation, and lifestyle. Eur J Oncol Nurs. 2011;15(3):213-20.

15. Mohile SG, Xian Y, Dale W, Fisher SG, Rodin M, Morrow GR, et al. Association of a cancer diagnosis with vulnerability and frailty in older Medicare beneficiaries. J Natl Cancer Inst. 2009;101(17):1206-15.

16. Baker F, Haffer SC, Denniston M. Health-related quality of life of cancer and noncancer patients in Medicare managed care. Cancer. 2003;97(3):674-81.

17. Hurria A, Togawa K, Mohile SG, Owusu C, Klepin HD, Gross CP, et al Predicting chemotherapy toxicity in older adults with cancer: a prospective multicenter study. J Clin Oncology. 2011;29(25):3457-65.

18. Extermann M, Boler I, Reich RR, Lyman GH, Brown RH, DeFelice J, et al. Predicting the risk of chemotherapy toxicity in older patients: the chemotherapy risk assessment scale for high-age patients (CRASH) score. Cancer. 2012;118(13):3377-86.

19. Repetto L. Greater risks of chemotherapy toxicity in elderly patients with cancer. J Support Oncol. 2003;1(4 Suppl 2):18-24.

20. Cruz-Jentoft AJ, Baeyens JP, Bauer JM, Boirie Y, Cederholm T, Landi F, et al. Sarcopenia: European consensus on definition and diagnosis: report of the European working group on sarcopenia in older people. Age Ageing. 2010; 39(4):412-23.

21. Fearon K, Strasser F, Anker SD, Bosaeus I, Bruera E, Fainsinger RL, et al. Definition and classification of cancer cachexia: an international consensus. Lancet Oncol. 2011;12(5):489-95.

22. Moses AW, Slater C, Preston T, Barber MD, Fearon KC. Reduced total energy expenditure and physical activity in cachectic patients with pancreatic cancer can be modulated by an energy and protein dense oral supplement enriched with n-3 fatty acids. Br J Cancer. 2004;90(5):996-1002.

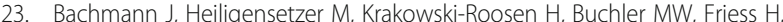
Martignoni ME. Cachexia worsens prognosis in patients with resectable pancreatic cancer. J Gastrointest Surgery. 2008;12(7):1193-201.

24. Dewys WD, Begg C, Lavin PT, Band PR, Bennett JM, Bertino JR, et al Prognostic effect of weight loss prior to chemotherapy in cancer patients. Eastern Cooperative Oncology Group. Am J Med. 1980;69(4):491-7.

25. Sun L, Quan XQ, Yu S. An epidemiological survey of Cachexia in advanced Cancer patients and analysis on its diagnostic and treatment status. Nutr Cancer. 2015;67(7):1056-62.

26. Sanchez-Lara K, Turcott JG, Juarez E, Guevara P, Nunez-Valencia C, OnateOcana LF, et al. Association of nutrition parameters including bioelectrical impedance and systemic inflammatory response with quality of life and prognosis in patients with advanced non-small-cell lung cancer: a prospective study. Nutr Cancer. 2012:64(4):526-34.

27. Fearon KC, Voss AC, Hustead DS. Definition of cancer cachexia: effect of weight loss, reduced food intake, and systemic inflammation on functional status and prognosis. Am J Clin Nutr. 2006;83(6):1345-50.

28. Stephens NA, Skipworth RJ, Gallagher IJ, Greig CA, Guttridge DC, Ross JA Evaluating potential biomarkers of cachexia and survival in skeletal muscle 
of upper gastrointestinal cancer patients. J Cachexia Sarcopenia Muscle. 2015;6(1):53-61.

29. Bouaziz W, Vogel T, Schmitt E, Kaltenbach G, Geny B, Lang PO. Health benefits of aerobic training programs in adults aged 70 and over: a systematic review. Arch Gerontol Geriatr. 2017;69:110-27.

30. Papa EV, Dong X, Hassan M. Resistance training for activity limitations in older adults with skeletal muscle function deficits: a systematic review. Clin Interv Aging. 2017;12:955-61.

31. Stewart VH, Saunders DH, Greig CA. Responsiveness of muscle size and strength to physical training in very elderly people: a systematic review. Scand J Med Sci Sports. 2014;24(1):e1-10.

32. Catalan-Matamoros D, Gomez-Conesa A, Stubbs B, Vancampfort D. Exercise improves depressive symptoms in older adults: an umbrella review of systematic reviews and meta-analyses. Psychiatry Res. 2016;244:202-9.

33. Jones LW, Eves ND, Haykowsky M, Freedland SJ, Mackey JR. Exercise intolerance in cancer and the role of exercise therapy to reverse dysfunction. Lancet Oncol. 2009;10(6):598-605.

34. Buffart LM, Kalter J, Sweegers MG, Courneya KS, Newton RU, Aaronson NK, et al. Effects and moderators of exercise on quality of life and physical function in patients with cancer: an individual patient data meta-analysis of 34 RCTs. Cancer Treat Rev. 2017:52:91-104.

35. Gerritsen JK, Vincent AJ. Exercise improves quality of life in patients with cancer: a systematic review and meta-analysis of randomised controlled trials. Br J Sports Med. 2016;50(13):796-803.

36. Adamsen L, Quist M, Andersen C, Moeller T, Herrstedt J, Kronborg D, et al. Effect of a multimodal high intensity exercise intervention in cancer patients undergoing chemotherapy: randomised controlled trial. BMJ. 2009;339:b3410.

37. Kilari D, Soto-Perez-de-Celis E, Mohile SG, Alibhai SM, Presley CJ, Wildes TM, et al. Designing exercise clinical trials for older adults with cancer: recommendations from 2015 Cancer and aging research group NCI U13 meeting. J Geriatr Oncol. 2016;7(4):293-304.

38. Granger CL, McDonald CF, Berney S, Chao C, Denehy L. Exercise intervention to improve exercise capacity and health related quality of life for patients with non-small cell lung cancer: a systematic review. Lung Cancer. 2011;72(2):139-53.

39. Cavalheri V, Tahirah F, Nonoyama M, Jenkins S, Hill K. Exercise training for people following lung resection for non-small cell lung cancer - a Cochrane systematic review. Cancer Treat Rev. 2014;40(4):585-94.

40. Quist M, Adamsen L, Rorth M, Laursen JH, Christensen KB, Langer SW. The impact of a multidimensional exercise intervention on physical and functional capacity, anxiety, and depression in patients with advanced-stage lung Cancer undergoing chemotherapy. Integr Cancer Ther. 2015;14(4):341-9.

41. Rueda JR, Sola I, Pascual A, Subirana Casacuberta M. Non-invasive interventions for improving well-being and quality of life in patients with lung cancer. Cochrane Database Syst Rev. 2011;(9):Cd004282.

42. Lai Y, Huang J, Yang M, Su J, Liu J, Che G. Seven-day intensive preoperative rehabilitation for elderly patients with lung cancer: a randomized controlled trial. J Surg Res. 2017;209:30-6.

43. Yeo TP, Burrell SA, Sauter PK, Kennedy EP, Lavu H, Leiby BE, et al. A progressive postresection walking program significantly improves fatigue and health-related quality of life in pancreas and periampullary cancer patients. J Am Coll Surg, 475. 2012;214(4):463 discussion 475-467.

44. Jensen W, Baumann FT, Stein A, Bloch W, Bokemeyer C, de Wit M, et al. Exercise training in patients with advanced gastrointestinal cancer undergoing palliative chemotherapy: a pilot study. Support Care Cancer. 2014;22(7):1797-806.

45. Slade SC, Dionne CE, Underwood M, Buchbinder R, Beck B, Bennell K, et al. Consensus on exercise reporting template (CERT): modified Delphi study. Phys Ther. 2016;96(10):1514-24.

46. Rikli R, Jones CJ. Senior fitness test manual -2nd edition. Champaign: Human Kinetics; 2001.

47. Jones CJ, Rikli RE, Beam WC. A 30-s chair-stand test as a measure of lower body strength in community-residing older adults. Res Q Exerc Sport. 1999; 70(2):113-9.

48. Rikli RE, Jones CJ. Development and validation of a functional fitness test for community-residing older adults. J Aging Phys Act. 1999;7:129-61.

49. Loenbro S, Dalgas U, Primdahl H, Overgaards J, Overgaard K. Feasibility and efficacy of progressive resistance training and dietary supplements in radiotherapy treated head and neck cancer patients -- the DAHANCA 25A study. Acta Oncol. 2013;52(2):310-8.
50. Guralnik JM, Ferrucci L, Pieper CF, Leveille SG, Markides KS, Ostir GV, et al. Lower extremity function and subsequent disability: consistency across studies, predictive models, and value of gait speed alone compared with the short physical performance battery. J Gerontol A Biol Sci Med Sci. 2000; 55(4):M221-31.

51. Cesari M, Kritchevsky SB, Penninx BW, Nicklas BJ, Simonsick EM, Newman $A B$, et al. Prognostic value of usual gait speed in well-functioning older people--results from the health, aging and body composition study. J Am Geriatr Soc. 2005;53(10):1675-80.

52. Schmidt $K$, Vogt $L$, Thiel $C$, Jäger $E$, Banzer $W$. Validity of the six-minute walk test in cancer patients. Int J Sports Med. 2013;34(7):631-6.

53. Rikli RE, Jones $\mathrm{CJ}$. The reliability and validity of a 6 -minute walk test as a measure of physical endurance in older adults. J Aging Phys Act. 1998;6: $363-75$.

54. Mathiowetz V, Weber K, Volland G, Kashman N. Reliability and validity of grip and pinch strength evaluations. J Hand Surg Am. 1984;9(2):222-6.

55. Kilgour RD, Vigano A, Trutschnigg B, Lucar E, Borod M, Morais JA. Handgrip strength predicts survival and is associated with markers of clinical and functional outcomes in advanced cancer patients. Support Care Cancer. 2013;21(12):3261-70.

56. Oken MM, Creech RH, Tormey DC, Horton J, Davis TE, MCFadden ET, et al. Toxicity and response criteria of the eastern cooperative oncology group. Am J Clin Oncol. 1982;5(6):649-55.

57. Cleeland CS, Mendoza TR, Wang XS, Chou C, Harle MT, Morrissey M, et al. Assessing symptom distress in cancer patients: the M.D. Anderson symptom inventory. Cancer. 2000;89(7):1634-46.

58. Aaronson NK, Ahmedzai S, Bergman B, Bullinger M, Cull A, Duez NJ, et al. The European Organization for Research and Treatment of Cancer QLQ-C30: a quality-of-life instrument for use in international clinical trials in oncology. J Natl Cancer Inst. 1993;85(5):365-76.

59. Zigmond AS, Snaith RP. The hospital anxiety and depression scale. Acta Psychiatr Scand. 1983;67(6):361-70.

60. Wright AA, Cook CE, Baxter GD, Dockerty JD, Abbott JH. A comparison of 3 methodological approaches to defining major clinically important improvement of 4 performance measures in patients with hip osteoarthritis. J Orthop Sports Phys Ther. 2011;41(5):319-27.

61. Litterini AJ, Fieler VK, Cavanaugh JT, Lee JQ. Differential effects of cardiovascular and resistance exercise on functional mobility in individuals with advanced cancer: a randomized trial. Arch Phys Med Rehabil. 2013: 94(12):2329-35.

62. Oldervoll LM, Loge JH, Lydersen S, Paltiel H, Asp MB, Nygaard UV, et al. Physical exercise for cancer patients with advanced disease: a randomized controlled trial. Oncologist. 2011;16(11):1649-57.

63. American College of Sports Medicine position stand. Progression models in resistance training for healthy adults. Med Sci Sports Exerc. 2009:41(3):687-708.

64. Sundhedsstyrelsen. Fysisk aktivitet - håndbog om forebyggelse og behandling 2011. Version 3.1. https://www.sst.dk/ /media/ 6B3A4AE698BC42139572C76C5854BA76.ashx Accessed 2 Feb 2017.

65. Schmitz KH, Courneya KS, Matthews C, Demark-Wahnefried W, Galvao DA, Pinto BM, et al. American College of Sports Medicine roundtable on exercise guidelines for cancer survivors. Med Sci Sports Exerc. 2010;42(7): $1409-26$.

66. Wildiers $\mathrm{H}$, Heeren $\mathrm{P}$, Puts $\mathrm{M}$, Topinkova $\mathrm{E}$, Janssen-Heijnen ML, Extermann M, et al. International Society of Geriatric Oncology consensus on geriatric assessment in older patients with cancer. J Clin Oncol. 2014;32(24):2595-603.

67. Sundhedsstyrelsen. Anbefalinger for den palliative indsats 2017. https:// www.sst.dk/da/sygdom-og-behandling/ /media/ 79CB83AB4DF74C80837BAAAD55347D0D.ashx Accessed 2 Feb 2017.

68. Tang CC, Von Ah D, Fulton JS. The Symptom Experience of Patients With Advanced Pancreatic Cancer: An Integrative Review. Cancer Nurs. 2018;41(1): 33-44.

69. Vainio A, Auvinen A. Prevalence of symptoms among patients with advanced cancer: an international collaborative study. Symptom Prevalence Group. J Pain Symptom Manage. 1996;12(1):3-10.

70. LeBlanc TW, Nickolich M, Rushing CN, Samsa GP, Locke SC, Abernethy AP. What bothers lung cancer patients the most? A prospective, longitudinal electronic patient-reported outcomes study in advanced non-small cell lung cancer. Support Care Cancer. 2015;23(12):3455-63. 
71. Larson PJ, Uchinuno A, Izumi S, Kawano A, Takemoto A, Shigeno M, et al. An integrated approach to symptom management. Nurs Health Sci. 1999;1: 203-10.

72. Bosaeus I, Daneryd P, Lundholm K. Dietary intake, resting energy expenditure, weight loss and survival in cancer patients. J Nutr. 2002;132(11 Suppl):3465s-65.

73. Andreyev HJ, Norman AR, Oates J, Cunningham D. Why do patients with weight loss have a worse outcome when undergoing chemotherapy for gastrointestinal malignancies? Eur J Cancer. 1998;34(4):503-9.

74. Lacau St Guily J, Bouvard E, Raynard B, Goldwasser F, Maget B, Prevost A, et al. NutriCancer: a French observational multicentre cross-sectional study of malnutrition in elderly patients with cancer. J Geriatr Oncol. 2018;9(1):74-80.

75. Miller W, Rollnick S. Motivational interviewing - helping people change 2nd edition edn. New York: Guilford Press; 2002

76. Spencer JC, Wheeler SB. A systematic review of motivational interviewing interventions in cancer patients and survivors. Patient Educ Couns. 2016; 99(7):1099-105.

77. Locke EA, Bryan JF. The effects of goal-setting, rule-learning, and knowledge of score on performance. Am J Psychol. 1966;79(3):451-7.

Ready to submit your research? Choose BMC and benefit from:

- fast, convenient online submission

- thorough peer review by experienced researchers in your field

- rapid publication on acceptance

- support for research data, including large and complex data types

- gold Open Access which fosters wider collaboration and increased citations

- maximum visibility for your research: over $100 \mathrm{M}$ website views per year

At $\mathrm{BMC}$, research is always in progress.

Learn more biomedcentral.com/submissions 